\title{
Asian Elephants (Elephas maximus) Discriminate Between Familiar and Unfamiliar Human Visual and Olfactory Cues
}

\author{
Emily J. Polla ${ }^{1,2 *}$, Cyril C. Grueter ${ }^{1}$, and Carolynn L. Smith ${ }^{3}$ \\ ${ }^{1}$ The University of Western Australia, Australia \\ ${ }^{2}$ Perth Zoo, Australia \\ ${ }^{3}$ Macquarie University, Australia \\ *Corresponding author (Email: emily.j.polla@gmail.com)
}

Citation - Polla, E. J., Grueter, C. C., \& Smith, C. L. (2018). Asian elephants (Elephas maximus) discriminate between familiar and unfamiliar human visual and olfactory cues. Animal Behavior and Cognition, 5(3), $279-291$. https://doi.org/10.26451/abc.05.03.03.2018.

\begin{abstract}
Social animals use individual identity cues to form and maintain social relationships with conspecifics. This ability to discriminate between individuals extends to heterospecifics in some social mammals. The aim of this study was to determine if Asian elephants (Elephas maximus) could differentiate between familiar and unfamiliar people using visual, auditory, and olfactory cues independently. Two female Asian elephants at the Perth Zoo were tested with stimuli generated from six humans. Video playbacks, auditory playbacks and pieces of worn shirts were used to present familiar and unfamiliar human stimuli to the elephants using a simultaneous two-choice task. Trunk reach duration and trunk reach frequency were used as measures of the elephants' interest in the stimuli. The elephants' trunk reach durations revealed a significant difference between familiar and unfamiliar human stimuli using visual cues alone, with significantly more trunk reaching toward familiar human stimuli. No significant difference in trunk reach duration was seen between familiar and unfamiliar human stimuli for auditory or olfactory cues. Trunk reach frequency revealed a significant difference between familiar and unfamiliar human stimuli for visual and olfactory stimuli, with a greater frequency of trunk reaching towards familiar stimuli for both modes. No significant difference in trunk reach frequency was seen between familiar and unfamiliar human stimuli for auditory cues. This is the first study to use video playbacks with any species of elephant and demonstrates a potential new method for cognitive testing in this species. The results suggest that familiar humans may be important to zoohoused Asian elephants.
\end{abstract}

Keywords - Discrimination; Elephant; Elephas maximus; Heterospecific; Unimodal; Visual; Olfactory

Distinguishing between individuals is crucial for the formation and maintenance of long-term social relationships, which are important for animals living in socially complex groups (Byrne, Bates, \& Moss, 2009; Cheney \& Seyfarth, 2007). Both Asian elephants and African elephants (Loxodonta africana) live in groups with high levels of social complexity and fluid fission-fusion dynamics (Byrne et al., 2009; de Silva \& Wittemyer, 2012; Moss, 1988). African elephants can distinguish up to 100 conspecifics from other elephants (McComb, Moss, Sayialel, \& Baker, 2000) and can recognize familiar individuals using olfactory cues (Bates et al., 2008). The discrimination of heterospecifics has been shown to extend to humans, in animals that regularly come into contact with them, with domestic cattle (Bos taurus: Taylor \& Davis, 1998), pigs (Sus scrofa: Brajon, Laforest, Bergeron, Tallet, \& Devillers, 2015) and mockingbirds (Mimus polyglottos: Levey et al., 2009) altering their behavioral responses towards specific humans based on the behavior of the human. Discrimination of human odors has been 
demonstrated in domestic dogs (Canis familiaris: Berns, Brooks, \& Spivak, 2015), human vocal cues in domestic cats (Felis catus: Saito \& Shinozuka, 2013), and human faces in domestic dogs and sheep (Canis familiaris: Mongillo, Scandurra, Kramer, \& Marinelli, 2017; Ovis aries: Peirce, Liegh, daCosta, \& Kendrick, 2001). Audio- visual cross modal recognition of humans has been demonstrated in squirrel monkeys (Saimiri sciureus, Adachi \& Fujita, 2007). The ability to discriminate individual humans allows animals to direct appropriate behaviors towards specific individuals (Bee, 2006). For example, pigeons are capable of discriminating between friendly and hostile humans (Belguermi et al., 2011).

Asian elephants have large brains (Hart, Hart, McCoy, \& Sarath, 2001), with an encephalization quotient similar to that of apes (Byrne et al., 2009; Eisenberg, 1981). They also possess a similar number of cortical neurons as humans. The number of cortical neurons has an even stronger positive correlation with intelligence in mammals than the encephalization quotient (Roth \& Dicke, 2005). Previous research shows that Asian elephants are capable of insightful problem solving (Foerder, Galloway, Barthel, Moore, \& Reiss, 2011) and using and modifying tools (Hart et al., 2001). There is evidence indicative of selfrecognition in Asian elephants (Plotnik, de Waal, \& Reiss, 2006). Asian elephants have also been found to display magnitude effects when determining relative quantities (Perdue, Talbot, Stone, \& Beran, 2012) Given the cognitive potential of Asian elephants, zoo-housed Asian elephants make appropriate test subjects for investigating cognitive tasks (Plotnik, de Waal, Moore, \& Reiss, 2009).

Previous research has examined the visual acuity (Shyan-Norwalt, Peterson, King, Staggs, \& Dale, 2010), odor discrimination ability (Arvidsson, Amundin, \& Laska, 2012), and auditory accuracy (Heffner \& Heffner, 1982) of elephants as well as the long-term memory for familiar sensory information (Arvidsson et al., 2012). Elephants have been shown to preference the use of olfaction over other sensory modalities for certain tasks, using olfactory but not auditory information to locate food (Plotnik, Shaw, Brubaker, Tiller, \& Clayton, 2014). African elephants have demonstrated the ability to match human scents to specific individuals (von Dürckheim et al., 2018). African elephants can also distinguish between human ethnic groups (Bates et al., 2007) and can determine ethnicity, gender and age from the acoustic cues present in human voices (McComb, Shannon, Sayialel, \& Moss, 2014). African elephants can adjust their visual signals based on the human's apparent attentiveness during interactions (Smet \& Byrne, 2014), can use human pointing as a cue to find hidden food (Smet \& Byrne, 2013; although Asian elephants failed to do so, Plotnik et al., 2014), and can discriminate between types of threatening stimuli (Soltis, King, Douglas-Hamilton, Vollrath, \& Savage, 2014). Wild Asian elephants have demonstrated the ability to distinguish between leopard and tiger growls, with elephants retreating silently from tiger growls (a potential predator of elephant calves) and retreating while vocalizing when exposed to leopard grows (which pose no threat, Thuppil \& Coss, 2013). Given the sensory and discriminatory abilities of elephants, it may be possible for Asian elephants to distinguish between different categories of humans.

Previous observational studies suggest that zoo-housed Asian elephants may form social bonds with familiar humans (Stoeger et al., 2012). However, heterospecific recognition has never been empirically tested in this species. This study tested whether Asian elephants could distinguish between familiar and unfamiliar humans using visual, auditory and olfactory cues independently. The goal of this study was to increase our knowledge of elephant cognition and how cognition is used by elephants to navigate their social life. Knowing more about how elephants use sensory information may also benefit the psychological welfare of captive elephants, which is a central part of captive animal management (Mason \& Veasey, 2010). These findings may suggest new methods for the introduction of new staff as well as improvements to existing behavioral enrichment and training programs.

\section{Methods}

\section{Participants}

Two female Asian elephants, Permai (23-years-old) and Tricia (56-years-old), housed together at the Perth Zoo, Western Australia, participated in this study. Permai arrived at the Zoo in 1992 and Tricia arrived in 1963. The elephants had been exposed to playbacks of wild elephant vocalizations in the past 
but had never been presented with human stimuli in previous studies. The elephants were housed in a free contact environment, where keepers enter the exhibit and interact in close proximity with the elephants (Desmond \& Laule, 1991).

\section{Materials}

Playback equipment. Two catering trolleys $(90 \mathrm{~cm}$ wide x $113 \mathrm{~cm}$ high x $50 \mathrm{~cm}$ deep) covered in blank cardboard were used to display the visual and auditory equipment. An M-Audio (BX5 D2) speaker was placed in the horizontal center of each trolley at a height of $81 \mathrm{~cm}$ from the ground to play back the auditory stimuli. The speakers were connected to a Mac Mini computer (Apple, Inc.) through a Behringer F Control audio interface (FCA202). Video stimuli were played through two 42" LG (42LM6410) LCD screens covered with $3 \mathrm{~mm}$ Perspex. One TV was placed on top of each trolley with the top of the TVs $1.77 \mathrm{~m}$ from the ground. The inside edge of each trolley was located $750 \mathrm{~mm}$ from the center of the testing area, with one olfactory stand made of unused $10 \mathrm{~mm}$ PVC reticulation piping and fishing line situated on the outside edge of each trolley (Figure 1). The elephants' responses were recorded by a Sony Handycam (HDR-PJ200E) on a $70 \mathrm{~cm}$ tripod situated on the midline between the two trolleys and a Ness Day/Night Exview IR camera attached to the roof of the barn.

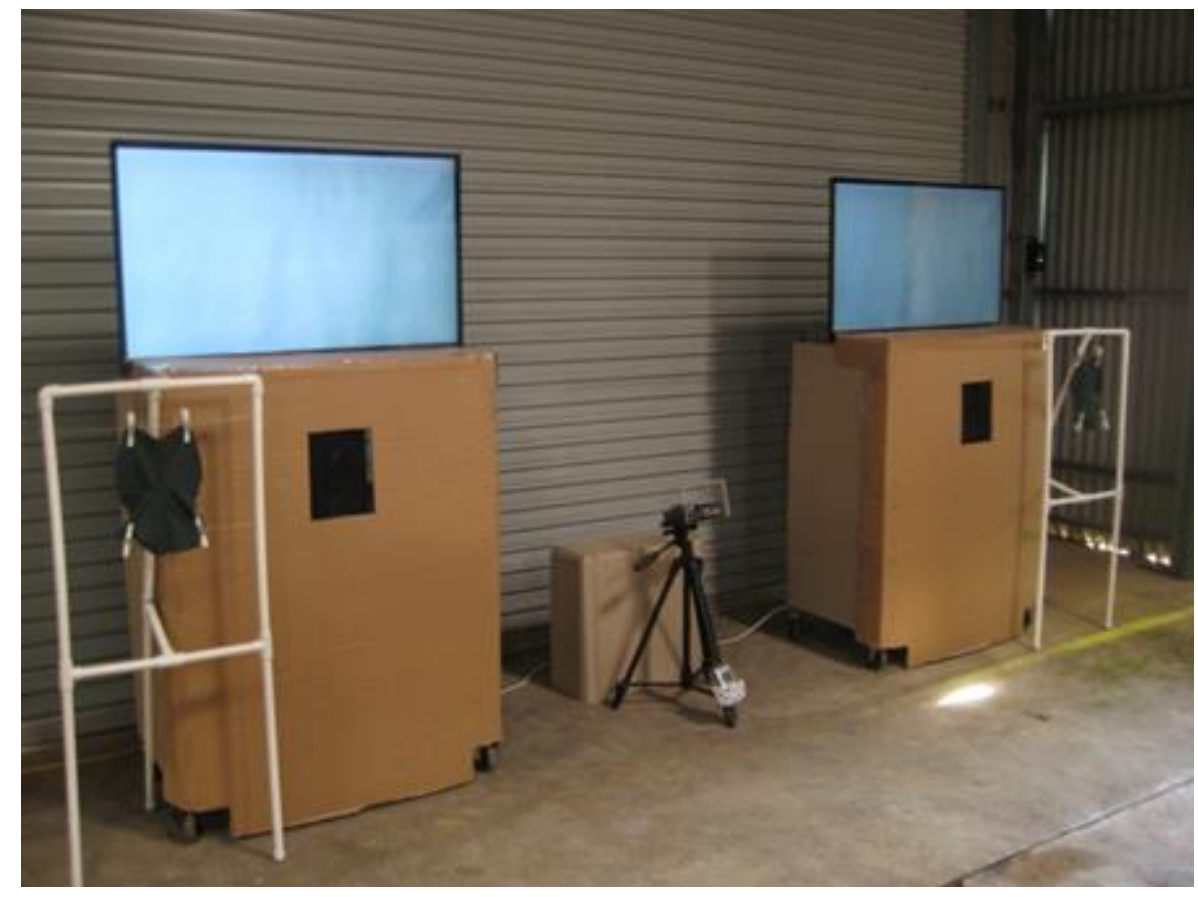

Figure 1. Experimental equipment in the location used for acclimation and unimodal trials at Perth Zoo. All equipment is beyond the maximum reach of the elephants' trunks ( $2.7 \mathrm{~m}$ from the enclosure).

Three familiar people (> 1 year as Perth Zoo elephant keeper) and three unfamiliar people (no exposure to the elephants) were matched in pairs for sex, hair length and color, build, and approximate age. Four male and two female humans were used to create the matched pairs of stimuli for the experiments.

Visual stimuli. Video stimuli have been successfully used since the 1990's to elicit natural behaviors from animals (Clark \& Uetz, 1990; Smith \& Evans, 2008). Hopper, Lambeth, and Schapiro (2012) revealed that chimpanzees' (Pan troglodytes) performance on a social learning task with a video demonstration and live demonstrator were comparable. Based on this previous research and Asian 
elephants' known sensory capabilities, video footage should be an appropriate source of visual information for studies investigating visual cues to identity, independent of other sensory modalities.

Human participants were filmed using a Sony (PMW-EX3) camera in front of a backdrop similar in color and texture to the walls of the elephant barn. Two 650W Arri Redhead lights were used to light the scene. Participants kept a neutral facial expression and maintained eye contact with an Ikan Studio Autocue teleprompter while following identical teleprompter instructions during filming for simple movements that would allow the elephants to view the participant's face from different angles (see Appendix). Eight 4-min videos were recorded from each participant so that each elephant was shown different footage, which was allocated randomly, and never saw the same footage twice. The final visual playback stimuli consisted of 1 min of the backdrop that the participants were filmed in front of, followed by a $0.05 \mathrm{~s}$ fade as the person appeared on the screen. After $4 \mathrm{~min}$, there was another $0.05 \mathrm{~s}$ fade and the backdrop reappeared. This type of fade has been successfully used with other vertebrates (Smith \& Evans, 2008). The elephants did not appear startled by the transition. During each visual trial, the designated pair appeared and faded out simultaneously from their respective LCD screen.

Auditory stimuli. Human participants repeated the word "hello" 80 times into a microphone at three second intervals (M-audio microtrack 24-bit/96 kHz). Hellos for each participant were combined with silence from the recording room to create a 4 min split stereo track for familiar/unfamiliar participant pairs using Audacity (2.04) and were recorded, edited and played back as .wav files at $48 \mathrm{kHz}$ and 24-bit rate PCM. Each stereo track consisted of $10 \mathrm{~s}$ of "hellos" (5 vocalizations, $2 \mathrm{~s}$ apart) from one participant followed by $20 \mathrm{~s}$ of room silence on one audio track followed by the same pattern vocalizations and silence from the other participant from the familiar/unfamiliar pair on the other track. This alternation of vocalizations between speakers was repeated until the end of the trial.

One word ("hello") was repeated to standardize the duration and tone of voice during the playback. Single word stimuli have been used in past studies to test discrimination between familiar and unfamiliar human voices (e.g., Adachi \& Fujita, 2007; Proops \& McComb, 2012). The audio was counterbalanced across both elephants so that the familiar and unfamiliar person was heard first an equal number of times. Each "hello" was selected randomly and used only once during playbacks to ensure that the elephants were responding to the person's voice rather than a particular characteristic of a specific auditory recording (McGregor, 2000).

Olfactory stimuli. The Perth Zoo shirts were washed together with the same detergent and line dried before being sealed in Zip Lock bags and distributed to the human participants. The human participants showered and slept in a clean Perth Zoo staff shirt overnight $(\sim 8 \mathrm{hr})$ without deodorant or perfume. Participants exercised vigorously for $10 \mathrm{~min}$ before removing the shirt. Participants placed the shirt back into the Zip Lock bag before collection by the researcher. The underarms of the shirt were then cut out to create two $30 \times 18 \mathrm{~cm}$ pieces and placed in a Zip Lock bag. Pieces were used on the same day as they were worn. Each elephant was presented with one underarm from the same shirt. The shirt pieces were removed from the bag immediately before each trial and pegged to a clean plastic presentation stand by the researcher while wearing latex gloves. The shirt pieces remained on the stands for the entire trial.

\section{Design and Procedure}

The elephants were tested in the main female elephant barn at Perth Zoo using the playback equipment described above (Figure 2). The barn had two concrete walls, a hydraulic door through which the elephants entered and a metal roof approximately $7 \mathrm{~m}$ high. The stall in which the animals were tested measured $5.7 \mathrm{~m} \times 10.2 \mathrm{~m}$ with two of the barn perimeter lengths made of cylindrical metal poles $0.12 \mathrm{~m}$ in diameter and $2.15 \mathrm{~m}$ high. The poles were $0.50 \mathrm{~m}$ apart, allowing elephants to reach their trunks through the fence. The elephant was led into the barn immediately prior to testing by an elephant keeper whose stimulus was not to be used in any of the trials. Each female was tested individually.

The equipment was placed out of trunk reach of the elephants, $2.7 \mathrm{~m}$ from the front of the enclosure (Figure 1). The keeper then left the elephant alone in the barn so that no keeping staff, researchers or other elephants were present during the trials. The elephants were acclimated to the 
experimental equipment and barn isolation in ten 10-min acclimation sessions. All equipment, including unworn pieces of the shirts, was present during all acclimation trials. The electronic equipment was turned on with no stimuli playing from the speakers. A plain grey background was played on both TVs during the acclimation sessions. All equipment present in the acclimation trails was also present in the experimental trials.

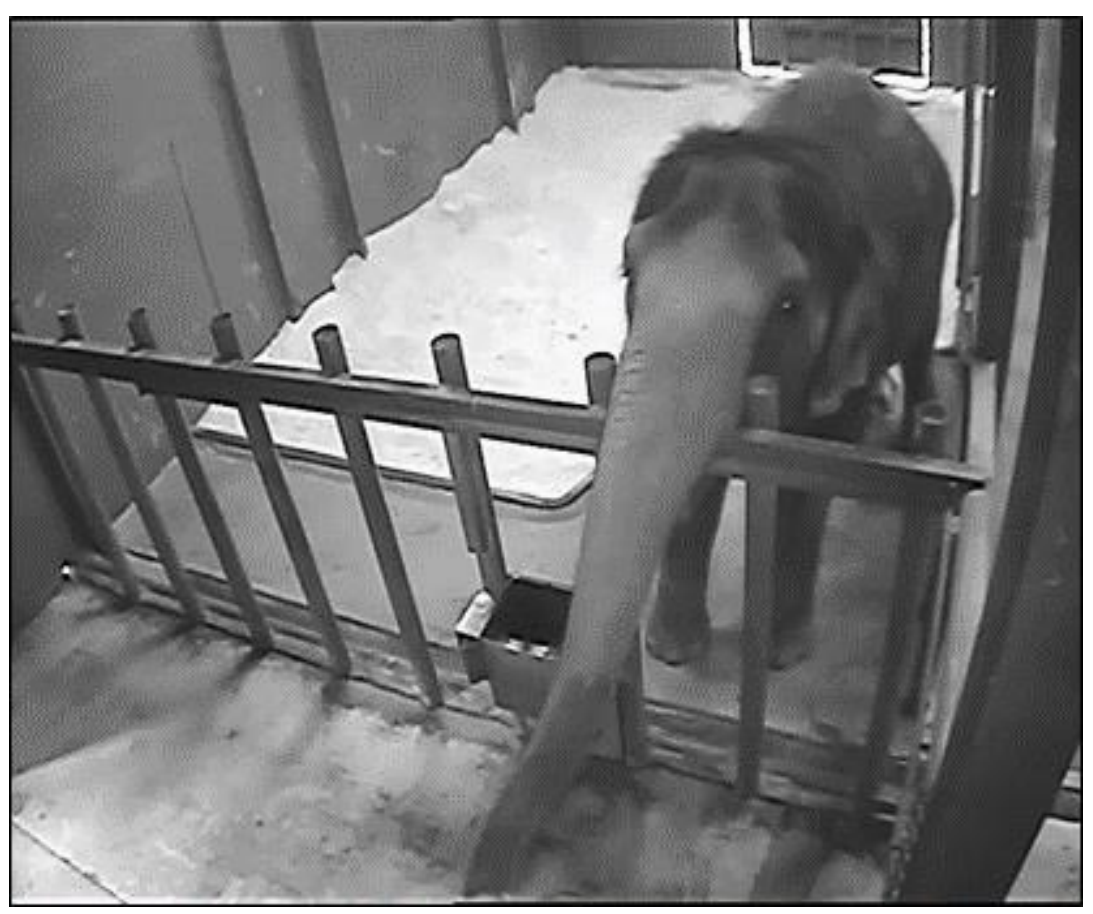

Figure 2. Photo of Permai trunk reaching towards the stimulus. The trunk tip is within 15 degrees of the stimulus center and greater than $80 \mathrm{~cm}$ horizontal distance from the elephant's face. Both trunk reaches above and below the horizontal enclosure bar were included in the total trunk reach duration.

In order to develop accurate scoring parameters for the video recordings of the elephants' trials, a preliminary study took place between the first three acclimation trials. The experimental equipment was removed and an elephant keeper, who was not a participant in the unimodal study, was filmed calling to and feeding each elephant individually while standing on the marks made for the location of unimodal equipment. The film revealed that light levels, kept low to prevent reflection from the TV screens, prevented eye movements from being accurately recorded, while elephant's head and ear movements were not consistent across preliminary study trials. Trunk reach duration towards the stimulus was identified as an appropriate measure of responsiveness due to consistency and use in previous studies (Bates et al., 2008). An elephant's trunk movement was scored as a trunk reach if the tip of the elephant's trunk was a minimum of $800 \mathrm{~mm}$ horizontal distance from the front of the elephant's face and if the trunk tip was within 15 degrees of the center of the stimulus (Figure 2). The angle was chosen as it was the widest angle elephants were observed reaching towards the keeper during the preliminary study. The horizontal distance was chosen as it differentiated trunk reaching towards the stimuli from other trunk movements, such as self-touching. Measurements of the elephants' heads, trunk lengths and enclosure items were taken and these life-size measurements were compared to the same items in the video playbacks, creating a measurement scale that allowed real-life trunk reach distances to be accurately determined from the video recordings.

During the experimental trials, one familiar and one unfamiliar stimulus from a human pair were presented from the same stimulus type. Each elephant completed two 4 min trials per day, with the exception of Day 1, where the first trial of the day was the final of the 10 acclimation sessions (Table 1). 
A total of nine experimental trials were completed by each elephant; one trial for each of the three modes (visual, auditory and olfactory) per human pair. The trial order, side of familiar stimuli, and the side that the keeper exited the barn were partially counterbalanced or alternated for each elephant (Table 1) to reduce order and stimulus position effects.

Table 1

Stimulus Presentation Order for each Stimulus Type and the Familiar/Unfamiliar Human Participant Pair used for the Trial.

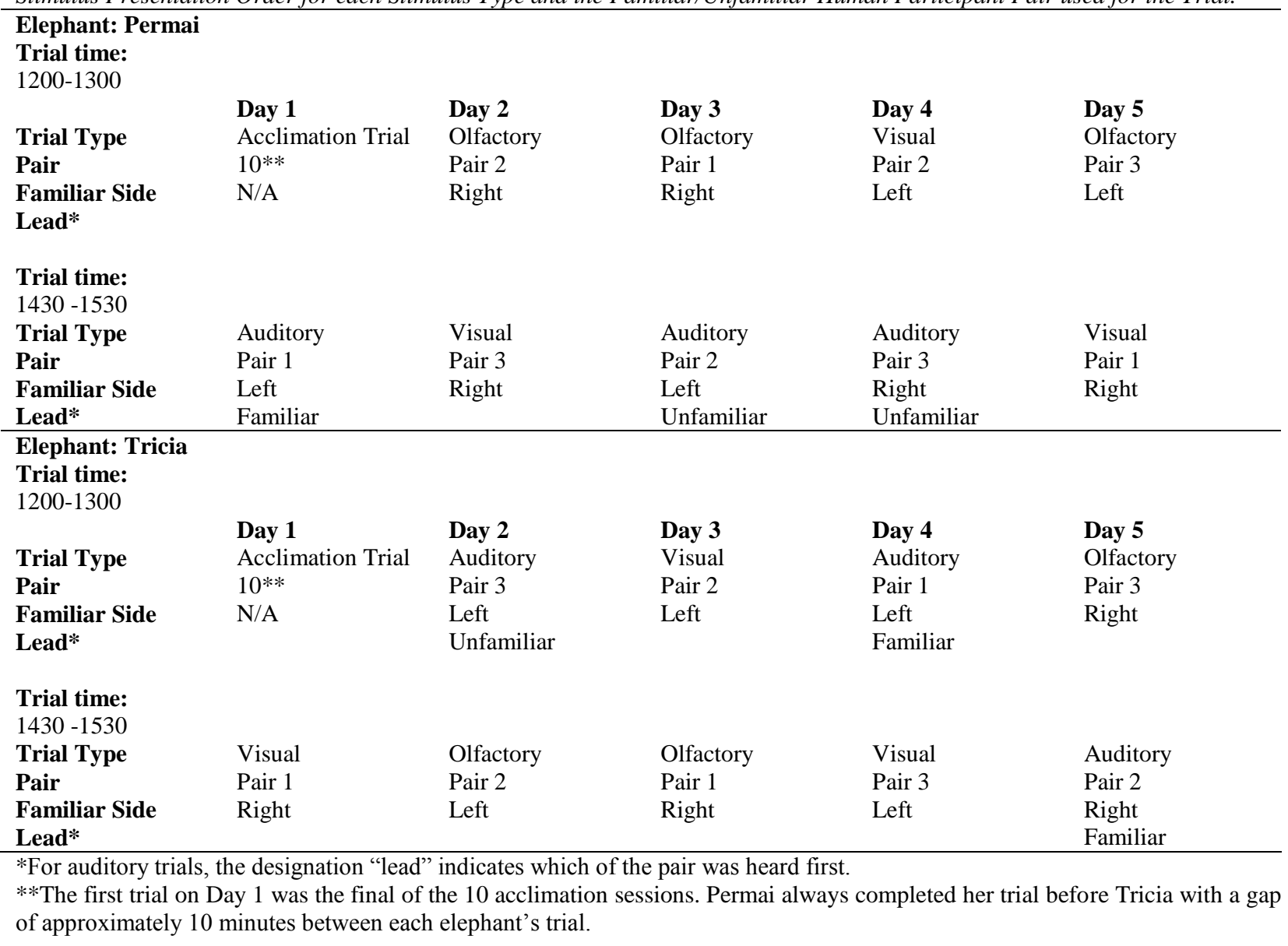

\section{Data Analysis}

Trunk reach duration (ms) was scored frame-by-frame (40 frames per second, PAL video standard) from the Ness Day/Night Exview IR camera using the editing program Avidemux (2.6.1). All recordings were scored blind to the experimental condition.

The trunk reach duration data from the acclimation trials for each elephant was analyzed using Spearman's Rank Correlation as a measure of the level of acclimation that had occurred. The trunk reach duration towards each side was also analyzed using Wilcoxon Sign-Rank test for each elephant to determine whether a side bias existed for either animal. These analyses took place in order to determine whether it was appropriate to combine the data from both elephants.

Sign tests were performed for the trunk reach duration data for each mode (visual, auditory and olfactory) on data from both elephants to test for discrimination between familiar and unfamiliar humans. Due to the nature of the data collected and small number of repeats per trial type per animal, it was not possible to take repeated measures into account for the duration data. Due to this, trunk reach frequency data was also analyzed for each mode (visual, auditory and olfactory) on data from both elephants using 
McNemar's test to account for repeated measures. As no previous studies have been completed suggesting preference for familiar or unfamiliar human stimuli, two-tailed tests were used.

\section{Results}

\section{Acclimation}

There was a significant negative relationship between Permai's total trunk reach duration and trial number for acclimation trials (Spearman's Rank Correlation $r_{s}=-0.697, p=.025$ ). Tricia's acclimation data revealed a trend towards a negative relationship $\left(r_{s}=-0.602, p=.066\right)$. The trunk reach duration towards each side was not significantly different for either elephant during the acclimation trials (Permai: Wilcoxon Signed-Rank $z=19, p=.678$; Tricia: $z=27.5, p=1.000$ ).

As both elephants followed the same trend for acclimation and neither elephant had a side bias, the data from both elephants' experimental trials (Table 2) were combined for analysis.

Table 2

Raw Data for each Experimental Trial.

\begin{tabular}{|c|c|c|c|c|c|c|c|}
\hline Elephant & $\begin{array}{c}\text { Trial } \\
\#\end{array}$ & $\begin{array}{l}\text { Trial } \\
\text { Type }\end{array}$ & $\begin{array}{l}\text { Trunk Reach } \\
\text { Duration } \\
\text { Familiar (s) } \\
\end{array}$ & $\begin{array}{c}\text { Trunk Reach } \\
\text { Duration } \\
\text { Unfamiliar (s) }\end{array}$ & $\begin{array}{c}\text { Trunk Reach } \\
\text { Frequency } \\
\text { Familiar } \\
\end{array}$ & $\begin{array}{c}\text { Trunk Reach } \\
\text { Frequency } \\
\text { Unfamiliar } \\
\end{array}$ & $\begin{array}{c}\text { Total Time } \\
\text { Oriented Towards } \\
\text { Stimuli (s) } \\
\end{array}$ \\
\hline Permai & 9 & visual & 2.447 & 2.247 & 1 & 1 & 79.477 \\
\hline Permai & 6 & visual & .802 & 0 & 1 & 0 & 12.998 \\
\hline Permai & 3 & visual & 20.266 & 0 & 4 & 0 & 114.983 \\
\hline Permai & 1 & auditory & 1.003 & 29.607 & 1 & 8 & 240.000 \\
\hline Permai & 5 & auditory & 6.258 & 26.074 & 3 & 13 & 240.000 \\
\hline Permai & 7 & auditory & .361 & 11.075 & 1 & 5 & 190.008 \\
\hline Permai & 4 & olfactory & 16.169 & 26.199 & 3 & 6 & 91.995 \\
\hline Permai & 2 & olfactory & 9.589 & .963 & 5 & 1 & 191.216 \\
\hline Permai & 8 & olfactory & 2.768 & 1.966 & 1 & 1 & 46.619 \\
\hline Tricia & 1 & visual & 17.035 & 10.432 & 7 & 3 & 240.000 \\
\hline Tricia & 4 & visual & 11.634 & 7.784 & 7 & 3 & 240.000 \\
\hline Tricia & 7 & visual & 15.811 & 8.163 & 8 & 5 & 240.000 \\
\hline Tricia & 6 & auditory & 7.143 & 0 & 4 & 0 & 168.302 \\
\hline Tricia & 9 & auditory & 24.356 & 1.645 & 11 & 1 & 240.000 \\
\hline Tricia & 2 & auditory & 10.791 & 7.463 & 6 & 3 & 240.000 \\
\hline Tricia & 5 & olfactory & 5.337 & 6.380 & 2 & 2 & 113.498 \\
\hline Tricia & 3 & olfactory & 0 & 23.910 & 0 & 7 & 126.417 \\
\hline Tricia & 8 & olfactory & 0 & 22.830 & 0 & 7 & 240.000 \\
\hline
\end{tabular}

\section{Trunk Reach Duration}

During experimental trials, the elephants reached towards the familiar visual stimulus for a significantly longer duration than the unfamiliar stimulus (Sign test $z_{1}=0, p=.031$; Figure 3). There was no significant difference in the response to the olfactory stimulus for trunk reach duration $\left(z_{l}=4, p=\right.$ .688). There was also no significant difference in the trunk reach duration response to the auditory stimulus $\left(z_{l}=3, p=1.000\right)$. 


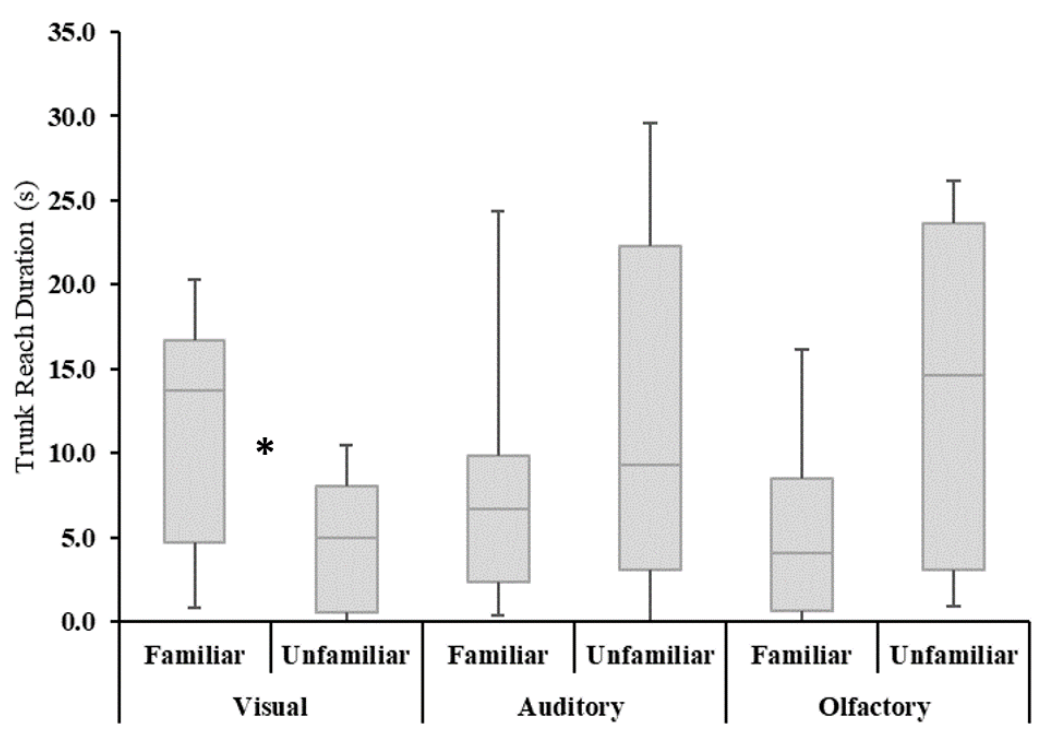

Figure 3. Trunk reach duration to each stimulus type. Duration of trunk reach (s) towards familiar and unfamiliar stimuli for each stimulus type by both elephants. The box plots show the median (central horizontal line), upper and lower interquartile range (outer bounds of the rectangle) and the maximum and minimum duration (whiskers). ${ }^{*} p<.05$.

\section{Trunk Reach Frequency}

The experimental trials revealed a significant difference in trunk reach frequency towards visual stimuli, with elephants reaching towards the familiar visual stimulus more frequently than the unfamiliar visual stimulus $\left(X^{2}{ }_{l}=5.625, p=.018\right.$; Figure 4). A significant difference was revealed for trunk reach frequency towards olfactory stimuli, with elephants reaching towards the unfamiliar olfactory stimulus more frequently than the familiar olfactory stimulus $\left(X^{2}{ }_{1}=4.114, p=.043\right.$; Figure 4). There was no significant difference in the trunk reach frequency response to the auditory stimulus $\left(X^{2}{ }_{l}=0.161, p=\right.$ $.689)$.

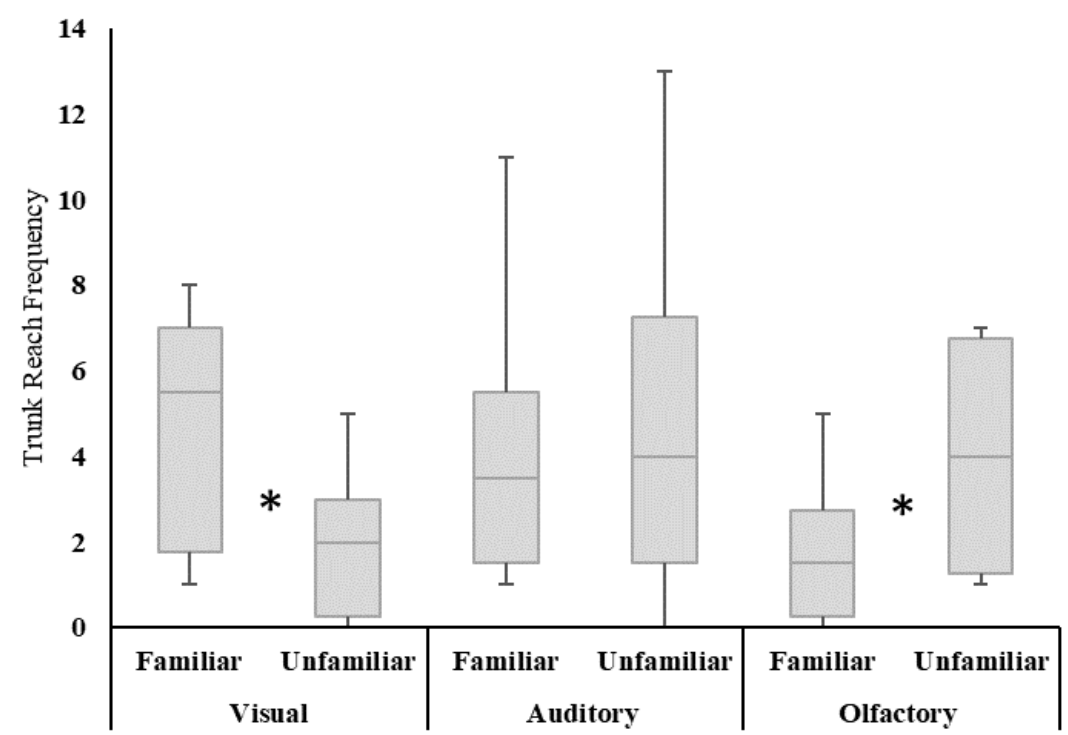

Figure 4. Trunk reach frequency to each stimulus type. Trunk reach frequency towards familiar and unfamiliar stimuli for each stimulus type by both elephants. The box plots show the median (central horizontal line), upper and lower interquartile range (outer bounds of the rectangle) and the maximum and minimum frequency (whiskers). ${ }^{*} p<.05$. 


\section{Discussion}

This study shows that Asian elephants can discriminate between familiar and unfamiliar humans using a visual stimulus alone (Figure 3; Figure 4), indicating that they have the capacity to discriminate visual identity cues from specific humans. Past research on the African elephants' visual system states that they can detect important conspecific behavioral cues, such as ear and trunk movements (Byrne et al., 2009; Kahl \& Armstrong, 2000) as well as important heterospecific behavioral cues, such as human pointing, face and body orientation (Smet \& Byrne, 2013, 2014); however, research by Plotnik et al. (2013) found that Asian elephants could not follow human pointing cues. The results of the current study suggest that Asian elephants are able to detect more subtle visual cues, which may be important for establishing and maintaining social bonds.

The elephants did not discriminate between a familiar and unfamiliar human using auditory stimuli. Examination of the individual elephants' responses to the auditory tests suggests that individual differences may explain these results (Table 2). Tricia tended to reach more towards familiar auditory stimuli whereas Permai exhibited the opposite behavior and, therefore, the combined results were not significant. The individual differences in response towards familiar or unfamiliar auditory stimuli seen in this study may be due to the individual preferences of the elephants, rather than an inability to distinguish. Further research with a larger sample size or trial number should be conducted to determine if Asian elephants are capable of discriminating between familiar and unfamiliar human auditory stimuli.

The Asian elephants in this study showed a greater trunk reach frequency towards unfamiliar olfactory stimuli (Figure 4). However, no significant difference was present between the trunk reach duration towards familiar and unfamiliar olfactory stimulus. The results for the frequency of trunk reaches support previous studies on Asian and African elephants' olfactory abilities. Previous studies on Asian elephants have shown that they can discriminate between odors with similar chemical structures (Arvidsson et al., 2012) and have long-term odor memory (Rasmussen \& Krishnamurthy, 2000). African elephants have also been shown to be capable of detecting human scent on cloths a distance of $10 \mathrm{~m}$ away (Bates et al., 2007). Taken together, these previous studies suggest that elephants use scents to gain information about their environment. The difference in the response measures shows the importance of using multiple measures where possible. Permai and Tricia displayed different generalized patterns of trunk reaching with Permai often trunk reaching towards the stimuli less frequently for a longer duration while Tricia often displayed shorter, more frequent trunk reaching towards the stimuli (Table 2). One possible explanation for this difference may be the difference in age between the two elephants, as reaching out with the trunk for a longer duration may be more physically demanding and therefore more likely to be seen in a younger animal. Further research with a larger sample size of Asian elephants with a diverse range of ages may provide insight as to whether trunk reach duration or frequency is a more reliable measure of attending towards stimuli.

Individual variation in response to identical conditions has been previously shown in Asian elephants (Fanson, Lynch, Miller, \& Keeley, 2013) and has been shown to affect responses in other species in recognition testing (Mulcahy \& Call, 2009). Previous research suggests that the elephants should have been capable of localizing and distinguishing between the brief human vocalizations (Heffner \& Heffner, 1982). However, recent research has found that Asian elephants used olfactory cues but not auditory cues to locate food over non-rewarding alternatives (Plotnik et al., 2014), which indicates that hearing may not be as important as smell for Asian elephants for some tasks. Repeating the study with a larger sample size may reveal the ability to discriminate between heterospecific individuals using auditory cues.

The results of this study show that the elephants attended more towards familiar visual stimuli, more towards unfamiliar olfactory stimuli and suggested individual variation may exist in the response to the type (familiar or unfamiliar) of auditory stimuli. The reason for this variation in attention towards the two different stimuli types across the different modes is unclear and further research may reveal why this occurs. This study is the first to show that Asian elephants can view and discriminate between videos on LCD screens. This new technique has the potential for use in other cognitive behavioral testing and for 
enrichment activities as a method of providing engaging visual stimuli. Given the sample size in this study and the potential for individual variation in response, we recommend further examination of Asian elephant's abilities in unimodal recognition tasks. A larger sample size may reveal the elephants' ability to differentiate between the voices of familiar and unfamiliar humans.

The results reveal previously unknown visual and olfactory discrimination abilities in zoo-housed Asian elephants. Recognition of heterospecifics suggests that familiar people are important for members of this social species living in zoo environments. Further research is required to identify whether the elephants used fine-grained cues, such as facial features, or movement cues to discriminate between familiar and unfamiliar humans. Future research could also determine if these visual and olfactory recognition abilities extend to conspecifics or wild Asian elephants.

\section{Acknowledgements}

We thank the staff at Perth Zoo, including the elephant team and the research staff. We are also grateful to A. Bruz for assistance in video and audio preparation and to the six anonymous participants.

\section{Ethical Approval}

Human research ethics approval was gained from the University of Western Australia (approval number RA/4/1/5920). Animal research and ethics approval was gained from the Perth Zoo Animal Research and Ethics Committees (approval number 2013-1).

\section{References}

Adachi, I., \& Fujita, K. (2007). Cross-modal representation of human caretakers in squirrel monkeys. Behavioral Processes, 74, 27-32. doi:10.1016/j.beproc.2006.09.004Arvidsson, J., Amundin, M., \& Laska, M. (2012). Successful acquisition of an olfactory discrimination test by Asian elephants Elephas maximus. Physiology and Behavior, 105, 809-881. http://dx.doi.org/10.1016/j.physbeh.2011.08.021

Bates, L. A., Sayialel, K. N., Njiraini, N. W., Moss, C, J., Poole, J. H., \& Byrne, R. W. (2007). Elephants classify human ethnic groups by odor and garment color. Current Biology, 17, 1938-1942. http://dx.doi.org/10.1016/j.cub.2007.09.060

Bates, L. A., Sayialel, K. N., Njiraini, N. W., Poole, J. H., Moss, C. J., \& Byrne, R. W. (2008). African elephants have expectations about the locations of out-of-sight family members. Biology Letters, 4, 34-36. http://dx.doi.org/10.1098/rsbl.2007.0529

Bee, M. A. (2006). Individual recognition in animal species. In K. Brown (Ed.), Encyclopedia of language and linguistics, $2^{\text {nd }}$ ed (pp. 617-626). Amsterdam: Elsevier.

Belguermi, A., Bovet, D., Pascal, A., Prévot-Julliard, A. C., Saint Jalme, M., ...Leboucher, G. (2011). Pigeons discriminate between human feeders. Animal Cognition, 14, 909-914. http://dx.doi.org/10.1007/s10071011-0420-7

Berns, G. S., Brooks, A. M., \& Spivak, M. (2015). Scent of the familiar: An fMRI study of canine brain responses to familiar and unfamiliar human and dog odors. Behavioural Processes, 110, 37-46. http://dx.doi.org/10.1016/j.beproc.2014.02.011

Brajon, S., Laforest, J., Bergeron, R., Tallet, C., \& Devillers, N. (2015). The perception of humans by piglets: Recognition of familiar handlers and generalisation to unfamiliar humans. Animal Cognition, 18, 12991316. http://dx.doi.org/10.1007/s10071-015-0900-2

Byrne, R. W., Bates, L. A., \& Moss, C. J. (2009). Elephant cognition in primate perspective. Comparative Cognition and Behavior Reviews, 4, 65-79. doi:10.3819/ccbr.2009.40009

Cheney, D. L., \& Seyfarth, R. M. (2007). Baboon metaphysics: The evolution of a social mind. Chicago: University of Chicago Press.

Clark, D. L., \& Uetz, G. W. (1990). Video image recognition by the jumping spider, Maevia inclemens (Araneae: Salticidae). Animal Behavior, 40, 884-890. http://dx.doi.org/10.1016/S0003-3472(05)80990 
de Silva, S., \& Wittemyer, G. (2012). A comparison of social organization in Asian elephants and African savannah elephants. International Journal of Primatology, 33, 1125-1141. http://dx.doi.org/10.1007/s10764-0119564-1

Desmond, T., \& Laule, G. (1991). Protected-contact elephant training. In: American Association of Zoological Parks and Aquariums National Conference Proceedings (pp. 606-613). San Diego: Active Environments Inc.

Eisenberg, J. E. (1981). The mammalian radiations: An analysis of trends in evolution, adaptation, and behavior. Chicago: University of Chicago Press.

Fanson, K. V., Lynch, M., Miller, G., \& Keeley, T. (2013). Response to long-distance relocation in Asian elephants (Elephas maximus): Monitoring adrenocortical activity via serum, urine, and feces. Eureopean Journal of Wildlife Research, 59, 655-664. http://dx.doi.org/10.1007/s10344-013-0718-7

Foerder, P., Galloway, M., Barthel, T., Moore, D. E. III, \& Reiss, D. (2011). Insightful problem solving in an Asian elephant. PLoS ONE, 6, e23251. http://dx.doi.org/10.1371/journal.pone.0023251

Hart, B. L., Hart, L. A., McCoy, M., \& Sarath, C. R. (2001). Cognitive behavior in Asian elephants: Use and modification of branches for fly switching. Animal Behavior, 62, 839-847. http://dx.doi.org/10.1006/anbe.2001.1815

Heffner, R. S., \& Heffner, H. E. (1982). Hearing in the elephant (Elephas maximus): absolute sensitivity, frequency discrimination, and sound localisation. Journal of Comparitive and Physiological Psychology, 96, 926944. http://dx.doi.org/10.1037/0735-7036.96.6.926

Hopper, L. M., Lambeth, S. P., \& Schapiro, S. J. (2012). An evaluation of the efficacy of video displays for use with chimpanzees (Pan troglodytes). American Journal of Primatology, 74, 442-449. http://dx.doi.org/10.1002/ajp.22001

Kahl, M. P., \& Armstrong, B. D. (2000). Visual and tactile displays in African elephants, Loxodonta africana: A progress report (1991-1997). Elephant, 2, 19-21. http://dx.doi.org/10.22237/elephant/1521732201

Levey, D. J., Londoño, G.A., Ungvari-Martin, J., Hiersoux, M. R., Jankowski, J. E., ...Robinson, S. K. (2009). Urban mockingbirds quickly learn to identify individual humans. Proceedings of the National Academy of Sciences, 106, 8959-8962. http://dx.doi.org/10.1073/pnas.0811422106

Mason, G. J., \& Veasey, J. S. (2010). How should the psychological well-being of zoo elephants be objectively investigated? Zoo Biology, 29, 237-255. http://dx.doi.org/10.1002/zoo.20256

McComb, K., Moss, C. J., Sayialel, S., \& Baker, L. (2000). Unusually extensive networks of vocal recognition in African elephants. Animal Behavior, 59, 1103-1109. http://dx.doi.org/10.1006/anbe.2000.1406

McComb, K. G., Shannon, G., Sayialel, K. N., \& Moss, C. (2014). Elephants can determine ethnicity, gender, and age from acoustic cues in human voices. Proceedings of the National Academy of Sciences, 111, 54335438. http://dx.doi.org/10.1073/pnas.1321543111

McGregor, P. K. (2000). Playback experiments: Design and analysis. Acta Ethologica, 3, 3-8. http://dx.doi.org $/ 10.1007 / \mathrm{s} 102110000023$

Mongillo, P., Scandurra, A., Kramer, R. S. S., \& Marinelli, L. (2017). Recognition of human faces by dogs (Canis familiaris) requires visibility of head contour. Animal Cognition, 20, 881-890. http://dx.doi.org/10.1007/s10071-017-1108-4

Moss, C. J. (1988). Elephant memories: Thirteen years in the life of an elephant family. London: Elm Tree Books.

Mulcahy, N. J., \& Call, J. (2009). The performance of bonobos (Pan paniscus), chimpanzees (Pan troglodytes), and orangutans (Pongo pygmaeus) in two versions of an object-choice task. Journal of Comparative Psychology, 123, 304-309. http://dx.doi.org/10.1037/a0016222

Peirce, J. W., Liegh, A. E., daCosta, A. P. C., \& Kendrick, K. M. (2001). Human face recognition in sheep: Lack of configurational coding and right hemisphere advantage. Behavioural Processes, 55, 13-26. http://dx.doi.org/10.1016/S0376-6357(01)00158-9

Perdue, B. M., Talbot, C. F., Stone, A. M., \& Beran, M. J. (2012). Putting the elephant back in the herd: Elephant relative quantity judgments match those of other species. Animal Cognition, 15, 955-961. http://dx.doi.org/10.1007/s10071-012-0521-y

Plotnik, J. M., de Waal, F. B. M., Moore, D. III \& Reiss, D. (2009). Self-recognition in the Asian elephant and future directions for cognitive research with elephants in zoological settings. Zoo Biology, 28, 1-13. http://dx.doi.org/10.1002/zoo.20257

Plotnik, J. M., de Waal, F. B. M., \& Reiss, D. (2006). Self-recognition in an Asian elephant. Proceedings of the National Academy of Sciences, 103, 17053-17057. http://dx.doi.org/10.1073/pnas.0608062103

Plotnik, J. M., Shaw, R. C., Brubaker, D. L., Tiller, L. N. \& Clayton, N. S. (2014). Thinking with their trunks: Elephants use smell but not sound to locate food and exclude nonrewarding alternatives. Animal Behaviour, 88, 91-98. http://dx.doi.org/10.1016/j.anbehav.2013.11.011 
Plotnik, J. M., Pokorny, J. J., Keratimanochaya, T., Webb, C., Beronja, H. F., ... Getz, D. (2013). Visual cues given by humans are not sufficient for Asian elephants (Elephas maximus) to find hidden food. PLoS ONE, 8, e61174. http://dx.doi.org/10.1371/journal.pone.0061174

Proops, L., \& McComb, K. (2012). Cross-modal individual recognition in domestic horses (Equus caballus) extends to familiar humans. Proceedings of the Royal Society B-Biological Sciences, 279, 3131-3138. http://dx.doi.org/10.1098/rspb.2012.0626

Rasmussen, L. E., \& Krishnamurthy, V. (2000). How chemical signals integrate Asian elephant society: The known and the unknown. Zoo Biology, 19, 405-423. http://dx.doi.org/10.1002/1098-2361

Roth, G., \& Dicke, U. (2005). Evolution of the brain and intelligence. Trends in Cognitive Sciences, 9, 250-257. http://dx.doi.org/10.1016/j.tics.2005.03.005

Saito, A., \& Shinozuka, K. (2013). Vocal recognition of owners by domestic cats (Felis catus). Animal Cognition, 16, 685-690. http://dx.doi.org/10.1007/s10071-013-0620-4

Shyan-Norwalt, M. R., Peterson, J., King, B. M., Staggs, T. E., \& Dale, R. H. (2010). Initial findings on visual acuity thresholds in an African elephant (Loxodonta africana). Zoo Biology, 29, 30-35. http://dx.doi.org/10.1002/zoo.20259

Smet, A. F., \& Byrne, R. W. (2013). African elephants can use human pointing cues to find hidden food. Current Biology, 23, 2033-2037. http://dx.doi.org/10.1016/j.cub.2013.08.037

Smet, A. F., \& Bryne, R. W. (2014). African elephants (Loxodonta africana) recognize visual attention from face and body orientation. Biology Letters, 10, http://dx.doi.org/10.1098/rsbl.2014.0428

Smith, C. L., \& Evans, C. S. (2008). Multimodal signaling in fowl, Gallus gallus. Journal of Experimental Biology, 211, 2052-2057. http://dx.doi.org/10.1242/jeb.017194

Soltis, J., King, L. E., Douglas-Hamilton, I., Vollrath, F., \& Savage, A. (2014). African elephant alarm calls distinguish between threats from humans and bees. PLoS ONE, 9, e89403. http://dx.doi.org/10.1371/journal.pone.0089403

Stoeger, A. S., Mietchen, D., Oh, S., de Silva, S., Herbst, C. T., ...Fitch, W. T. (2012). An Asian elephant imitates human speech. Current Biology, 22, 2144-2148. http://dx.doi.org/10.1016/j.cub.2012.09.022

Taylor, A. A., \& Davis, H. (1998). Individual humans as discriminative stimuli for cattle (Bos taurus). Applied Animal Behavior Science, 58, 13-21. http://dx.doi.org/10.1016/S0168-1591(97)00061-0

Thuppil, V. \& Coss, R. G. (2013). Wild Asian elephants distinguish aggressive tiger and leopard growls according to perceived danger. Biology Letters, 9. http://dx.doi.org/10.1098/rsbl.2013.0518.

von Dürckheim, K. E. M., Hoffman, L. C., Leslie, A., Hensman , M. C., Hensman, S., ...Lee, S. (2018). African elephants (Loxodonta africana) display remarkable olfactory acuity in human scent matching to sample performance. Applied Animal Behavior Science, 200, 123-129.

https://doi.org/10.1016/j.applanim.2017.12.004 


\section{Appendix}

Below are the teleprompter instructions used to collect visual stimuli from participants. Participants maintained a neutral facial expression and eye contact with the teleprompter while following the instructions printed in white lettering on a black background on each of the 61 slides. Boxes designated as $<$ Blank $>$ were a black background with no letters. During these times, the participants head was in a neutral position directly in line with the teleprompter. Numbers in brackets represent the duration (s) which the instruction was on the screen. The participant held the instructed position for the duration of the time the instruction was displayed.

\begin{tabular}{|c|c|c|c|c|c|}
\hline$\langle$ Blank> (3) & $\begin{array}{l}\text { Lift your head } \\
\text { up (4) }\end{array}$ & $\begin{array}{c}\text { Drop your } \\
\text { head down (4) }\end{array}$ & $\begin{array}{l}\text { Lift your head } \\
\text { up (4) }\end{array}$ & $\begin{array}{c}\text { Drop your } \\
\text { head down (4) }\end{array}$ & $<$ Blank> (3) \\
\hline $\begin{array}{l}\text { Tilt your head } \\
\text { up (5) }\end{array}$ & $<$ Blank> (4) & $\begin{array}{c}\text { Drop your } \\
\text { head down (6) }\end{array}$ & $<$ Blank> (3) & $\begin{array}{c}\text { Shrug your } \\
\text { shoulders once } \\
\text { (4) }\end{array}$ & $<$ Blank $>(2)$ \\
\hline $\begin{array}{l}\text { Lift your head } \\
\text { up (7) }\end{array}$ & $<$ Blank> (3) & $\begin{array}{l}\text { Wink right eye } \\
\text { once (3) }\end{array}$ & $<$ Blank $>(2)$ & $\begin{array}{l}\text { Tilt your head } \\
\text { right }(4)\end{array}$ & $\begin{array}{l}\text { Lift your head } \\
\text { up (7) }\end{array}$ \\
\hline$\langle$ Blank> (2) & $\begin{array}{l}\text { Tilt your head } \\
\text { left (3) }\end{array}$ & $\langle$ Blank> (3) & $\begin{array}{l}\text { Drop your } \\
\text { head down to } \\
\text { the right (6) }\end{array}$ & $<$ Blank $>(2)$ & $\begin{array}{c}\text { Close your } \\
\text { eyes for } 2 \\
\text { seconds, then } \\
\text { open them (5) }\end{array}$ \\
\hline$<$ Blank> (2) & $\begin{array}{l}\text { Lift your head } \\
\text { up to the right } \\
\text { (6) }\end{array}$ & $<$ Blank> (4) & $\begin{array}{l}\text { Tilt your head } \\
\text { right }(5)\end{array}$ & $<$ Blank $>$ (3) & $\begin{array}{c}\text { Wink left eye } \\
\text { once (3) }\end{array}$ \\
\hline$<$ Blank> (3) & $\begin{array}{c}\text { Drop your } \\
\text { head down to } \\
\text { the left (7) }\end{array}$ & $<$ Blank> (4) & $\begin{array}{c}\text { Drop your } \\
\text { head down (4) }\end{array}$ & $\begin{array}{l}\text { Lift your head } \\
\text { up (4) }\end{array}$ & $<$ Blank $>(2)$ \\
\hline $\begin{array}{l}\text { Tilt your head } \\
\text { right }(5)\end{array}$ & $\langle$ Blank> (3) & $\begin{array}{l}\text { Lift your head } \\
\text { up (7) }\end{array}$ & $<$ Blank> (3) & $\begin{array}{c}\text { Drop your } \\
\text { head down (6) }\end{array}$ & $<$ Blank> (2) \\
\hline $\begin{array}{c}\text { Shrug your } \\
\text { shoulders once } \\
\text { (3) }\end{array}$ & $<$ Blank> (2) & $\begin{array}{l}\text { Lift your head } \\
\text { left (6) }\end{array}$ & $<$ Blank> (5) & $\begin{array}{c}\text { Drop your } \\
\text { head down (6) }\end{array}$ & $<$ Blank> (3) \\
\hline
\end{tabular}

